\title{
Evaluation of Morphological and Molecular Diversity among South Asian Germplasms of Cucumis sativus and Cucumis melo
}

\author{
Chi Zhang, ${ }^{1}$ Arun S. Pratap, ${ }^{2}$ S. Natarajan, ${ }^{3}$ L. Pugalendhi, ${ }^{3}$ Shinji Kikuchi, ${ }^{1}$ Hidenori Sassa, ${ }^{1}$ \\ Natesan Senthil, ${ }^{2}$ and Takato Koba ${ }^{1}$ \\ ${ }^{1}$ Laboratory of Genetics, Graduate School of Horticulture, Chiba University, Matsudo, Chiba 271-8510, Japan \\ ${ }^{2}$ Department of Plant Molecular Biology and Biotechnology, Centre for Plant Molecular Biology, Tamil Nadu Agricultural University, \\ Tamil Nadu, Coinbatore 641003, India \\ ${ }^{3}$ Faculty of Horticulture, Tamil Nadu Agricultural University, Tamil Nadu, Coinbatore 641003, India \\ Correspondence should be addressed to Takato Koba, koba@faculty.chiba-u.jp
}

Received 17 July 2012; Accepted 12 August 2012

Academic Editors: G. M. Dal Bello, L. F. Goulao, L. Velasco, and X. Xu

Copyright ( $) 2012$ Chi Zhang et al. This is an open access article distributed under the Creative Commons Attribution License, which permits unrestricted use, distribution, and reproduction in any medium, provided the original work is properly cited.

Cucumber, Cucumis sativus $(2 n=2 x=14)$, and melon, Cucumis melo $(2 n=2 x=24)$, are two common vegetable crops worldwide. The present study evaluated eighteen Cucumis accessions (nine C. sativus and nine C. melo) that were collected from three South Asian countries that have the most diversity of Cucumis. Nine quantitative and twenty-three qualitative characteristics were measured. The values of fruit weight displayed the biggest divergence among the nine quantitative traits and much variation was displayed in twenty-three qualitative traits among eighteen accessions. For eight morphological quantitative traits other than fruit weight, eighteen accessions were divided into three groups by using Principle Component Analysis and K-means cluster analysis. Also, two chloroplast genes $r b c L$ and mat $K$ of eighteen accessions were sequenced. Combined sequences were subjected to construct phylogenetic trees by Neighbor-Joining and Maximum Likelihood methods. Topologies of nine melon accessions were same in these two methods and nine cucumber accessions showed difference. The genetic distances among each of $C$. sativus and C. melo accessions were not high. We conclude that the genetic relationship among the eighteen accessions used in this study is not distant although they display significant morphological variations. The information on novel Cucumis germplasms provided here would contribute to breeding program as well as evolutional study in Cucumis.

\section{Introduction}

Cucumber, Cucumis sativus $(2 n=2 x=14)$, and melon, Cucumis melo $(2 n=2 x=24)$, are two common vegetable crops worldwide, which are both within the 20 most important vegetables [1]. Within the genus Cucumis, two groups (African group and Asian Group) are accepted. They are defined by geographic origin and chromosome number. Geographically, chromosome number of the African group is $2 n=2 x=24$. Africa, which contains the most numerous wild species, was assumed to be the place of origin of C. melo [2]. C. sativus is indigenous to South Asia and estimated to be domesticated about 300 years ago and was soon cultivated in the south and east of the Himalayas. Diversity in $C$. sativus, the Asian group, is not abundant as that in C. melo, the African group. Cucumber, C. sativus, is thought to be the representative of Asian group with the chromosome number $2 n=14[3,4]$. On the other hand, a recent study proposed a different opinion about the origin of C. melo and C. sativus. Sebastian et al. proposed that melon and cucumber were both of Asian origin and had numerous relatives in Australia and around the Indian Ocean which were overlooked previously [5].

It was known that there are thirty subspecies in C. melo, but only two varieties in C. sativus (C. sativus var. sativus and C. sativus var. hardwickii). C. sativus var. hardwickii $(2 n=14)$ is a wild, sympatric botanical variety of $C$. sativus var. sativus, which grows in the foothills of Himalayas mountains. This botanical variety has the multiple fruiting and branching habits which are not present in C. sativus var. sativus. C. sativus var. hardwickii is cross-compatible with C. sativus var. sativus. Therefore, C. sativus var. hardwickii 
has a potential for increasing the genetic diversity available for breeding commercial cucumber [6].

C. melo is thought to contain the most diverse varieties in the genus Cucumis [7]. Significant morphological variations exist in fruit traits such as color, size, shape, texture, and taste. In 2005, 67 Japanese melon cultivars were evaluated by RAPD and SSR markers. These cultivars were clustered to three horticulture variety groups: Group Cantalupensis, Group Inodorus, and Group Conomon [8]. In China, the important secondary center of diversity, the genetic diversity of C. melo was firstly assessed by Luan et al. [9]. Sixtyeight Chinese C. melo cultivars were evaluated by RAPD markers, and the results indicated that the Chinese accessions were seem to be rich resources of genetic diversity for plant improvement. Furthermore, to show the genetic diversity of Chinese Hami melon, 120 melon accessions, including 24 accessions of Hami melon, were analyzed by RAPD markers and the accessions of Hami melon were classified into the large-seed type [10]. In C. sativus, 16 selected cucumber cultivars were divided into four groups by evaluating the traits related to fruit flavor such as taste, aroma, and dry matter, and the correlations among these traits were confirmed [11]. Recently, a high density (97.5\% of chromosomes were covered) genetic map of cucumber was constructed, which was composed of 1,369 markers, including 1,152 SSR, 192 SRAP, 21 SCAR, and one STS locus [12]. Genetic diversity assessments and linkage map construction can increase the effectiveness of breeding programs [13].

Elucidating the phylogenetic relationships in the genus Cucumis is of great importance, because the closest relatives and natural composition can provide valuable information to improve melon and cucumber breeding [14]. By analyzing combined chloroplast sequences for 123 of the 130 genera of Cucurbitaceae, it was concluded that C. sativus evolved within an Australian/Asian clade and was phylogenetically far from C. melo than its relationship considered based on the current morphological classification [15]. Recently, by using DNA sequences from plastid and nuclear markers for 100 accessions from Africa, Australia, and Asia, it was shown that melon and cucumber are both of Asian origin and have some species-level relatives in Australia which were overlooked previously and further investigation of wild species should be concentrated in Asia and Australia [5].

Here, we evaluate genetic diversity in eighteen accessions of C. sativus and C. melo collected from South Asia. Also, the phylogenetic relationships are proposed based on the molecular data. Importance of genetic diversity for the purpose of crop improvement and evolutionary relationships are discussed.

\section{Materials and Methods}

2.1. Plant Materials. The materials used in this study comprised of eighteen genotypes of cucumber and melon collected from south Asian countries, most of which are from India (Table 1). The field work was conducted at College Orchard, Horticultural College and Research Institute, Tamil Nadu Agricultural University, Coimbatore, India. All of the eighteen accessions were planted with two replications inside
TABLE 1: Cucumber and melon accessions analyzed in this study.

\begin{tabular}{lcccc}
\hline Acc. No. & Germplasm & Spp. & Source & Country \\
\hline 1 & AAUC 2 & C. sativus & IIVR & India \\
2 & Andaman & C. melo & TNAU & India \\
3 & CM 1 & C. melo & TNAU & India \\
4 & Cus $125 / 71$ & C. sativus & CGN & China \\
5 & IC 4079 & C. sativus & CGN & India \\
6 & JL 3 Dhillon & C. sativus & CGN & India \\
7 & Long Green & C. sativus & CGN & India \\
8 & Mayilam & C. melo & TNAU & India \\
9 & Muskmelon Orange & C. melo & TNAU & India \\
10 & Mysore & C. melo & TNAU & India \\
11 & N 78 & C. melo & NBPGR & India \\
12 & Nanhai 2 Aouri & C. sativus & CGN & China \\
13 & Nepal Local & C. sativus & CGN & Nepal \\
14 & Olakkur & C. melo & TNAU & India \\
15 & Perundurai & C. sativus & TNAU & India \\
16 & Pudukkottai & C. melo & TNAU & India \\
17 & Shantung Thorny & C. sativus & CGN & China \\
18 & Theni & C. melo & TNAU & India \\
\hline
\end{tabular}

IIVR: India Institute of Vegetable Research

TNAU: Tamil Nadu Agriculture University

CGN: The Centre for Genetic Resources, the Netherlands

NBPGR: National Bureau of Plant Genetic Resources.

the shade net house and each replication had eight plants. All the recommended crop production and protection measures were adopted for raising a healthy crop.

\subsection{Evaluation of Quantitative and Qualitative Characters.} Morphological characters were recorded using five plants in each replication according to combined standards as described by National Bureau of Plant Genetic Resources (NBPGR). In total, 32 traits including nine quantitative and 23 qualitative characters were recorded, which are shown in Table 2 with their abbreviations.

2.3. Extraction of DNA. Genomic DNA was extracted from fresh leaves. Seeds were sown on filter paper in petri dish and grown in room temperature. A week-old seedlings were ground by using mortar and pestle in liquid nitrogen to fine powder and genomic DNA was extracted by using the CTAB method [16]. DNA samples were diluted to $5 \mathrm{ng} / \mu \mathrm{L}$ for polymerase chain reaction (PCR) amplification.

2.4. $r b c L$ and matK Gene Sequencing. PCR amplification was performed in a $10 \mu \mathrm{L}$ mixture containing $5 \mathrm{ng}$ genomic DNA, $0.01 \mu \mathrm{mol}$ primer, $0.4 \mathrm{mmol}$ dNTP, $0.05 \mathrm{U}$ Ex Taq (Takara, Japan), 1x PCR Buffer $2 \mathrm{mM} \mathrm{MgCl} 2$ (Takara, Japan). PCR reaction was performed in Takara PCR thermal cycler (Takara, Japan) and the cycle can be described as an initial denaturing step at $95^{\circ} \mathrm{C}$ for $5 \mathrm{~min}$, then 30 cycles of at $95^{\circ} \mathrm{C}$ for $30 \mathrm{sec}, 55^{\circ} \mathrm{C}$ for $30 \mathrm{sec}$, and $72^{\circ} \mathrm{C}$ for $25 \mathrm{sec}$. The final extension step was at $72^{\circ} \mathrm{C}$ for $10 \mathrm{~min}$. The PCR products were subjected to sequencing by using ABI 3130 Genetic Analyzer. Primers used in PCR and sequencing are shown 
TABLE 2: Characters observed and their abbreviations and standards.

\begin{tabular}{|c|c|c|}
\hline Character & Abb. & Standards \\
\hline Fruit weight $(\mathrm{g})$ & FW & The weight of fruits at fully ripe stage \\
\hline Peduncle length $(\mathrm{cm})$ & PL & The length from the base to fruit intersects peduncle \\
\hline Fruit length $(\mathrm{cm})$ & $\mathrm{FL}$ & The length from stalk end to the tip of the fruit \\
\hline Fruit girth $(\mathrm{cm})$ & FG & The girth at the middle portion \\
\hline Leaf length $(\mathrm{cm})$ & LL & The length from the tip to the leaf intersects petiole \\
\hline No. of primary branches & NPB & The number of branches borne on the main stem \\
\hline Leaf width & LW & The width at the broadest place of the leaf \\
\hline Internodal length $(\mathrm{cm})$ & IL & The length between two subsequent nodes \\
\hline Leaf Petiole length $(\mathrm{cm})$ & LPL & The length from the base of to the intersects petiole \\
\hline Plant growth & PG & Determinate, semideterminate, and indeterminate \\
\hline Stem shape & SS & Round, angular, and others \\
\hline Stem color & SC & Yellow, light green, green, dark green, and others \\
\hline Stem pubescence density & SPD & Sparse, medium, and dense \\
\hline Stem pubescence type & SPT & Soft, intermediate, and hard \\
\hline Leaf shape & LS & Orbicular, ovate, elliptical, reniform, cordate, triangular, entire, trilobite, pentalobate, and others \\
\hline Leaf margin & LM & Crenate, denticulate, entire, lobate, serrate, serrulate, spiny, undulate, and others \\
\hline Leaf color & LC & Light green, green, dark green, and others \\
\hline Leaf glossiness & LG & Dull, intermediate, and glossy \\
\hline Leaf pubescence density & LPD & Sparse, medium, and dense \\
\hline Leaf pubescence type & LPT & Soft, intermediate, and hard \\
\hline Flower color & FC & White, cream, yellow, orange, and others \\
\hline Fruit shape & FS & Globular, flattened, oblate, elliptical, pyriform, ovate, acorn, elongated, and others \\
\hline Stem end fruit shape & SFS & Depressed, flattened, rounded, and pointed \\
\hline Blossom end fruit shape & BEFS & Depressed, flattened, rounded, and pointed \\
\hline Fruit skin luster & FSL & Matt, intermediate, glossy, and others \\
\hline Fruit skin texture & FST & Smooth, rough, spiny, and others \\
\hline Fruit skin hardness & FSH & Soft, intermediate, hard, and others \\
\hline Predominant fruit skin color & PFSC & White, yellow, cream, pale green, green, dark green, orange, brown, grey, and others \\
\hline Secondary fruit skin color & SFSC & Absent, white, yellow, cream, pale green, green, dark green, orange, brown, grey, and others \\
\hline Secondary skin color pattern & SSCP & Absent, spotted, striped, netted, short streaked, long Streaked, and others \\
\hline Fruit mesocarp color & FMC & White, cream, green, orange, and others \\
\hline Seed color & SC & White, cream white, yellow, light brown, and others \\
\hline
\end{tabular}

TABLE 3: Primers used in PCR and sequencing.

\begin{tabular}{lc}
\hline Primer & \multicolumn{1}{c}{ Sequence } \\
\hline matK (Forward) & $5^{\prime}$-CTATATCCACTTATCTTTCAGGAGT-3' \\
matK (Reverse) & $5^{\prime}$-AAAGTTCTAGCACAAGAAAGTCGA-3' \\
$r b c L$ (Forward) & $5^{\prime}$-ATGTCACCACAAACAGAAACTAAAGC-3' \\
$r b c L$ (Reverse) & $5^{\prime}$-CTACGTCTGGAAGACCTGCGAATCC-3' \\
\hline
\end{tabular}

in Table 3. Consensus sequences were assembled and edited by using the program GENETYX-MAC version 14 (Genetyx, Japan) followed by manual adjustments.

2.5. Data Analysis. Principal Component Analysis (PCA) and k-means cluster analysis was performed by using $\mathrm{R}$ version 2.15.0 with bpca package for statistical computing. Phylogenetic analysis was performed under neighborjoining (NJ) and maximum likelihood (ML) methods. Sequences of $r b c L$ and matK were aligned with "clustalw2" on the website: http://www.ebi.ac.uk/Tools/msa/clustalw2/. The resulting aligned data matrix was prepared in MEGA 5.05. Bootstrap method is taken for the test of phylogeny. The number of bootstrap replications was 1000 . The model of NJ tree was maximum composite likelihood, and the model of ML tree was Tamura-Nei model.

\section{Results and Discussion}

3.1. Quantitative and Qualitative Characterization. Fruit appearances of eighteen accessions are shown in Figures 1 and 2, and their morphological performances are shown in Tables 4 and 5. For the nine quantitative characters, there was a large divergence among the values of fruit weight. ,drafC. melo "N78" and C. melo "Andaman" had the biggest fruit weights, $1,390 \mathrm{~g}$ and $1,350 \mathrm{~g}$, respectively. These two values exceeded all the other accessions ranging from $210 \mathrm{~g}$ of C. sativus "Long Green" to $850 \mathrm{~g}$ C. melo "Theni." C. melo cultivars had bigger fruit weights than those of $C$. sativus 


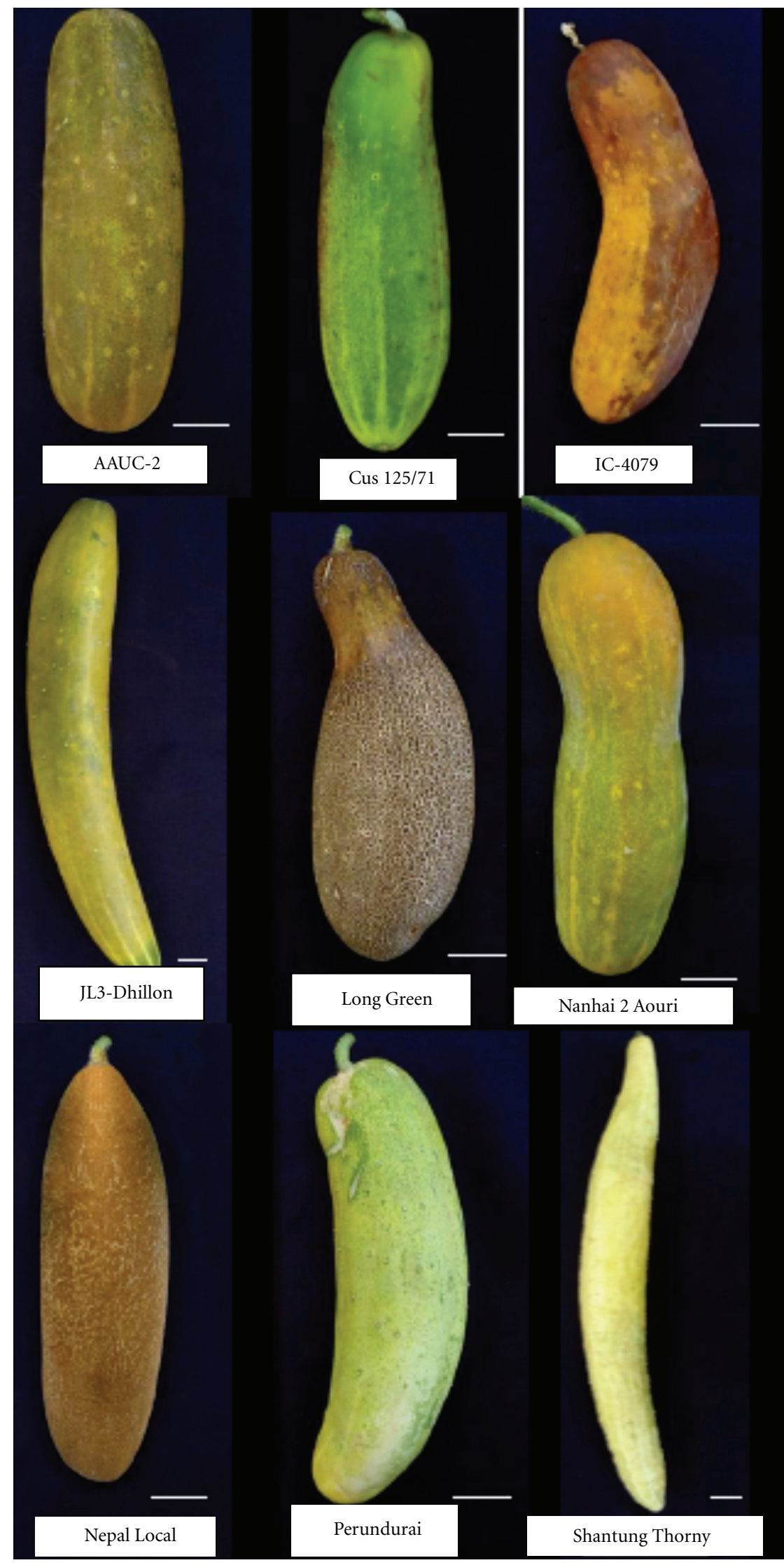

FIgure 1: Photographs of fruits of Cucumis sativus accessions used in the present study. Scale: $5 \mathrm{~cm}$. 


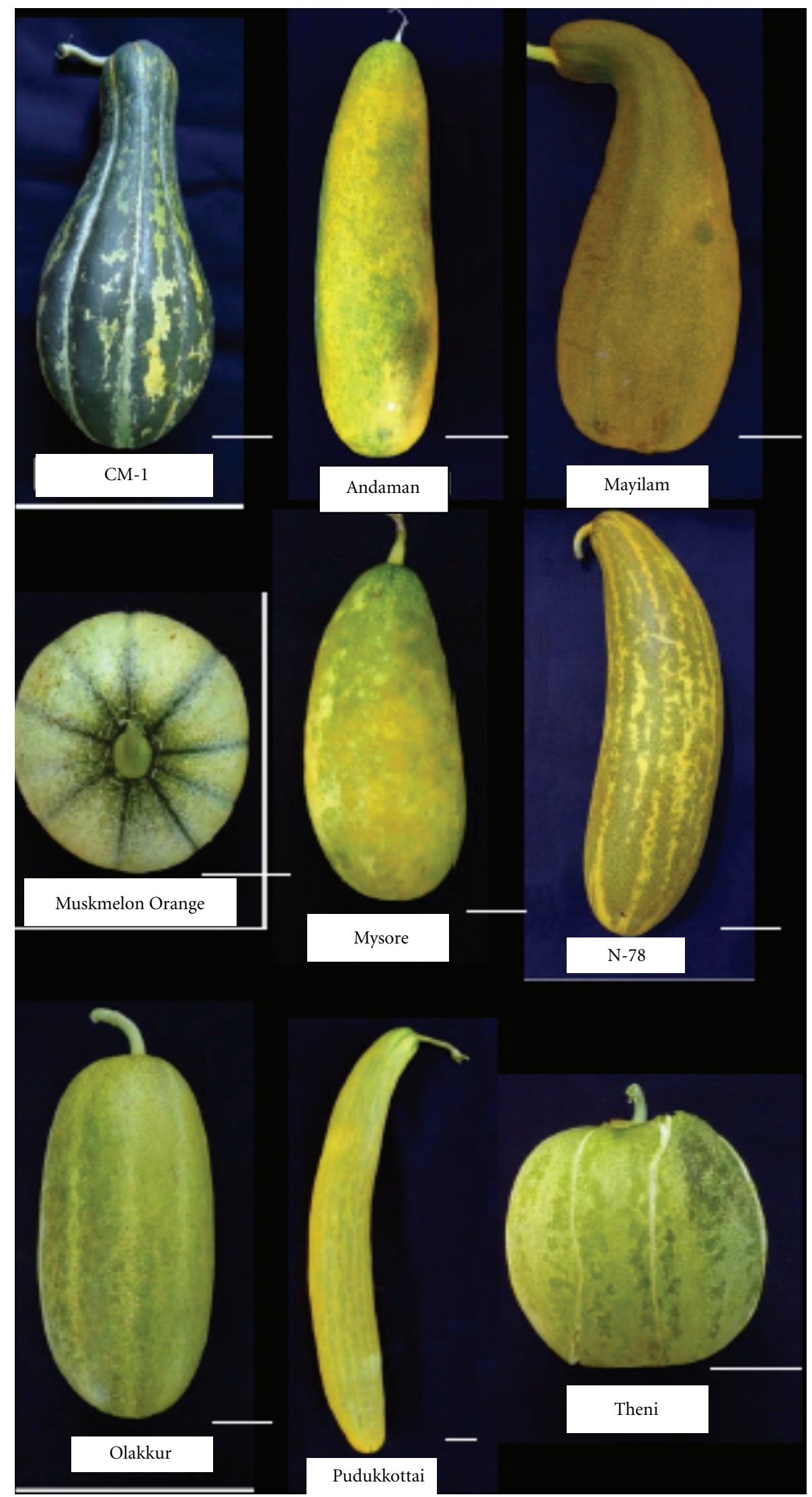

Figure 2: Photographs of fruits of Cucumis melo accessions used in the present study. Scale: $5 \mathrm{~cm}$. 
TABLE 4: The values on 9 quantitative characters of 18 accessions.

\begin{tabular}{|c|c|c|c|c|c|c|c|c|c|c|}
\hline Accession & Species & $\begin{array}{l}\text { FW } \\
(\mathrm{g})\end{array}$ & $\begin{array}{c}\text { PL } \\
(\mathrm{cm})\end{array}$ & $\begin{array}{c}\mathrm{FL} \\
(\mathrm{cm})\end{array}$ & $\begin{array}{c}\mathrm{FG} \\
(\mathrm{cm})\end{array}$ & $\begin{array}{c}\mathrm{LL} \\
(\mathrm{cm})\end{array}$ & $\begin{array}{c}\text { LW } \\
(\mathrm{cm})\end{array}$ & NPB & $\begin{array}{c}\text { IL } \\
(\mathrm{cm})\end{array}$ & $\begin{array}{l}\text { LPL } \\
(\mathrm{cm})\end{array}$ \\
\hline Cus $125 / 71$ & CS & 330 & 2.9 & 21.5 & 14.9 & 12.7 & 16.9 & 10.5 & 7.5 & 11.9 \\
\hline Long Green & CS & 210 & 6.1 & 17.3 & 16.9 & 12.5 & 17.1 & 6.5 & 4.9 & 17.3 \\
\hline JL-3 Dhillon & CS & 500 & 1.6 & 36.5 & 15.5 & 14.8 & 16.1 & 8.5 & 8.7 & 10.4 \\
\hline Nanhai 2 Aouri & CS & 230 & 3.6 & 16.9 & 15.3 & 13.9 & 15.9 & 6.5 & 9.3 & 9.7 \\
\hline Nepal Local & CS & 590 & 2.9 & 22.5 & 20.4 & 15.5 & 16.1 & 9.5 & 8.2 & 9.9 \\
\hline Shantung Thorny & CS & 360 & 1.3 & 35.9 & 14.8 & 15.5 & 18.3 & 9.5 & 12.1 & 10.3 \\
\hline AAUC-2 & CS & 790 & 3.3 & 24.3 & 18.7 & 15.7 & 20.1 & 8.5 & 14.5 & 15.3 \\
\hline Perundurai & CS & 400 & 2.5 & 23.9 & 18.3 & 12.7 & 17.5 & 12.5 & 8.5 & 12.5 \\
\hline IC-4079 & CS & 390 & 2.5 & 26.9 & 21.1 & 14.3 & 16.5 & 5.5 & 9.9 & 9.9 \\
\hline M & & 422.22 & 2.96 & 25.07 & 17.32 & 14.17 & 17.16 & 8.61 & 9.28 & 11.91 \\
\hline $\mathrm{SD}$ & & 182.12 & 1.38 & 7.06 & 2.41 & 1.29 & 1.34 & 2.21 & 2.73 & 2.71 \\
\hline CV \% & & $43 \%$ & $47 \%$ & $28 \%$ & $14 \%$ & $9 \%$ & $8 \%$ & $26 \%$ & $29 \%$ & $23 \%$ \\
\hline N-78 & $\mathrm{CM}$ & 1390 & 2.9 & 32.9 & 21.3 & 14.9 & 13.3 & 10.5 & 9.3 & 12.7 \\
\hline Mysore & $\mathrm{CM}$ & 290 & 3.3 & 21.3 & 24.2 & 8.2 & 12.7 & 5.5 & 5.6 & 7.5 \\
\hline CM-1 & $\mathrm{CM}$ & 820 & 7.1 & 33.7 & 39.3 & 14.3 & 16.3 & 8.5 & 12.2 & 8.6 \\
\hline Olakkur & $\mathrm{CM}$ & 640 & 3.9 & 22.7 & 26.3 & 13.5 & 13.3 & 5.5 & 8.5 & 12.3 \\
\hline Mayilam & $\mathrm{CM}$ & 770 & 5.6 & 30.3 & 27.9 & 13.7 & 15.5 & 6.5 & 7.7 & 11.9 \\
\hline Muskmelon Orange & $\mathrm{CM}$ & 520 & 3.1 & 14 & 35.3 & 11.9 & 14.5 & 9.5 & 9.1 & 13.6 \\
\hline Pudukkottai & $\mathrm{CM}$ & 795 & 5.3 & 46.3 & 18.9 & 12.1 & 14.4 & 6.5 & 7.9 & 11.7 \\
\hline Theni & $\mathrm{CM}$ & 850 & 2.6 & 18.9 & 39.3 & 14.9 & 17.7 & 8.5 & 6.5 & 14.3 \\
\hline Andaman & $\mathrm{CM}$ & 1350 & 3.2 & 40.7 & 29.9 & 14.6 & 17.9 & 12.5 & 10.6 & 14.7 \\
\hline M & & 825 & 4.11 & 28.97 & 29.15 & 13.12 & 15.06 & 8.16 & 8.6 & 825 \\
\hline $\mathrm{SD}$ & & 355.82 & 1.53 & 10.61 & 7.46 & 2.15 & 1.91 & 2.39 & 2.01 & 355.82 \\
\hline $\mathrm{CV} \%$ & & $43 \%$ & $37 \%$ & $37 \%$ & $26 \%$ & $16 \%$ & $13 \%$ & $29 \%$ & $23 \%$ & $43 \%$ \\
\hline
\end{tabular}

(Note) M: Mean, SD: Standard Deviation, CV: Coefficient of Variance, CS: C. sativus, CM: C. melo.

cultivars. C. melo accessions were almost above $500 \mathrm{~g}$ and the mean was $825 \mathrm{~g}$. On the other hand, C. sativus accessions were $420 \mathrm{~g}$ on average and $400 \mathrm{~g}$ less than C. melo. The exceptions were C. melo "Mysore" and C. sativus "AAUC-2", being the lightest $C$. melo and the heaviest $C$. sativus, with the weights of $290 \mathrm{~g}$ and $790 \mathrm{~g}$, respectively (Table 4). LópezSesé et al. reported that the mean fruit weight for a collection of 125 Spanish accessions was $1.5 \mathrm{~kg}$, while the mean fruit weight of Villaconejos landraces also from Spain was $2.08 \mathrm{~kg}$ [17]. It was also reported that the variability in fruit weight among Spanish varieties was 0.8 to $4.95 \mathrm{~kg}$ [18]. The range of fruit weight in the present study was 0.29 to $1.39 \mathrm{~kg}$, not as heavy as the Spanish group. The difference might be due to the different collection region, as well as the different breeding process in the long history of cultivation between the Mediterranean region and south Asian region.

The other eight quantitative traits did not show significant difference as fruit weight. We divided these traits into two groups, namely, fruit-related traits and stem, and leaf-related traits. The first group included fruit length, fruit girth, and peduncle length. According to the results of fruit girth and length, it was shown that the fruit size of $C$. melo was bigger than $C$. sativus except one cucumber accession "Shantung Thorny," which was bigger than C. melo "Mysore". "CM-1" and "Andaman" were the biggest ones in melon accessions. The second group were the traits including leaf width, leaf length, number of primary branches, intermodal length, and leaf petiole length, which showed smaller variance than fruit-related characters.

By Principal Component Analysis (PCA) and k-means cluster analysis, eight quantitative values were covered by three principle components (PC1, PC2, and PC3). Contribution of variables in each principle components was calculated (Table 6). Fruit length and fruit girth dominated in PC1 and PC2, respectively. Five characters, number of primary branches, internodal length, leaf petiole length, leaf length, and leaf width, had the similar contribution to PC3. Based on the result of principle component analysis, eighteen accessions were classified into three groups (Figure 3). Group 1 contained nine accessions (seven $C$. sativus accessions: AAUC-2, Perundurai, Nepal Local, IC-4079, Cus125/71, Long Green, and Nanhai2 Aouri and two C. melo accessions: Olakkur and Mysore) and Group2 contained six accessions (two C. sativus accessions: Shantung Thorny and JL-3 Dhillon and four C. melo accessions: Andaman, N-78, Pudukkottai, and Mayilam). Group 3 contained three $C$. melo accessions (CM-1, Theni, and Muskmelon Orange). The relative dispersion among accessions within Group2 was 
TABLE 5: Characteristics of the 18 accessions on 23 qualitative traits.

\begin{tabular}{|c|c|c|c|c|c|c|c|c|c|}
\hline Accession & Species & $\mathrm{PL}$ & SS & SC & SPD & SPT & LS & LM & $\mathrm{LC}$ \\
\hline Cus $125 / 71$ & CS & Indeterminate & Angular & Dark green & Medium & Hard & Entire & SPINY & Dark green \\
\hline Long Green & CS & Indeterminate & Angular & Light green & Medium & Hard & Entire & SPINY & Green \\
\hline JL-3 Dhillon & CS & Indeterminate & Angular & Dark green & Dense & Intermediate & Entire & SPINY & Dark green \\
\hline Nanhai 2 Aouri & CS & Indeterminate & Angular & Dark green & Medium & Hard & Entire & SPINY & Dark green \\
\hline Nepal Local & CS & Indeterminate & Angular & Dark green & Dense & Intermediate & Cordate & OTHERS & Dark green \\
\hline Shantung Thorny & CS & Indeterminate & Angular & Dark green & Medium & Hard & Entire & SPINY & Dark green \\
\hline AAUC-2 & CS & Indeterminate & Angular & Green & Sparse & Intermediate & Entire & SPINY & Dark green \\
\hline Perundurai & CS & Indeterminate & Angular & Dark green & Dense & Intermediate & Entire & SPINY & Green \\
\hline IC-4079 & CS & Indeterminate & Angular & Dark green & Dense & Intermediate & Entire & SPINY & Dark green \\
\hline N-78 & $\mathrm{CM}$ & Indeterminate & Angular & Green & Medium & Hard & Entire & SPINY & Light green \\
\hline Mysore & $\mathrm{CM}$ & Indeterminate & Angular & Green & Medium & Hard & Triangular & SPINY & Light green \\
\hline CM-1 & $\mathrm{CM}$ & Indeterminate & Angular & Dark green & Medium & Hard & Entire & SPINY & Green \\
\hline Olakkur & $\mathrm{CM}$ & Indeterminate & Angular & Green & Medium & Hard & Reniform & UNDULATE & Light green \\
\hline Mayilam & $\mathrm{CM}$ & Indeterminate & Angular & Green & Medium & Hard & Pentalobate & LOBATE & Light green \\
\hline Muskmelon Orange & $\mathrm{CM}$ & Indeterminate & Angular & Green & Medium & Hard & Pentalobate & LOBATE & Light green \\
\hline Pudukkottai & $\mathrm{CM}$ & Indeterminate & Angular & Dark green & Medium & Hard & Reniform & ENTIRE & Light green \\
\hline Theni & $\mathrm{CM}$ & Indeterminate & Angular & Green & Medium & Hard & Reniform & ENTIRE & Light green \\
\hline Andaman & $\mathrm{CM}$ & Indeterminate & Angular & Green & Medium & Intermediate & Cordate & SPINY & Light green \\
\hline Accession & Species & LG & & LPD & LPT & $\mathrm{FC}$ & FS & SFS & BEFS \\
\hline Cus $125 / 71$ & CS & Intermediate & & Dense & Soft & Yellow & Elongated & Rounded & Pointed \\
\hline Long Green & CS & Intermediate & & parse & Soft & Yellow & Elongated & Rounded & Rounded \\
\hline JL-3 Dhillon & CS & Intermediate & & Dense & Soft & Yellow & Elongated & Pointed & Pointed \\
\hline Nanhai 2 Aouri & CS & Glossy & & Dense & Soft & Yellow & Elongated & Rounded & Rounded \\
\hline Nepal Local & CS & Glossy & & edium & Hard & Yellow & Elongated & Rounded & Rounded \\
\hline Shantung Thorny & CS & Glossy & & Dense & Soft & Yellow & Elongated & Pointed & Pointed \\
\hline AAUC-2 & CS & Glossy & & Dense & Soft & Yellow & Others & Flattened & Flattened \\
\hline Perundurai & CS & Dull & & Dense & Soft & Yellow & Elongated & Flattened & Rounded \\
\hline IC-4079 & CS & Intermediate & & Dense & Soft & Yellow & Elongated & Rounded & Pointed \\
\hline $\mathrm{N}-78$ & $\mathrm{CM}$ & Intermediate & & edium & Hard & Yellow & Elongated & Pointed & Rounded \\
\hline Mysore & $\mathrm{CM}$ & Intermediate & & Dense & Soft & Yellow & Elliptical & Pointed & Rounded \\
\hline CM-1 & $\mathrm{CM}$ & Intermediate & & Dense & Soft & Yellow & Pyriform & Rounded & Rounded \\
\hline Olakkur & $\mathrm{CM}$ & Intermediate & & edium & Intermediate & Yellow & Others & Flattened & Flattened \\
\hline Mayilam & $\mathrm{CM}$ & Intermediate & & Pense & Soft & Yellow & Pyriform & Pointed & Depressed \\
\hline Muskmelon Orange & $\mathrm{CM}$ & Dull & & Dense & Soft & Yellow & Globular & Flattened & Flattened \\
\hline Pudukkottai & $\mathrm{CM}$ & Intermediate & & Dense & Soft & Yellow & Elongated & Rounded & Rounded \\
\hline Theni & $\mathrm{CM}$ & Intermediate & & parse & Intermediate & Yellow & Globular & Flattened & Depressed \\
\hline Andaman & $\mathrm{CM}$ & Intermediate & & edium & Hard & Yellow & Elongated & Pointed & Rounded \\
\hline Accession & Species & FSL & FST & FSH & PFSC & SFSC & SSCP & FMC & SC \\
\hline Cus $125 / 71$ & CS & Glossy & Spiny & Hard & Dark green & Pale green & Cream & Spotted & White \\
\hline Long Green & CS & Intermediate & Rough & Hard & Brown & White & Green & Striped & Green \\
\hline JL-3 Dhillon & CS & Intermediate & Spiny & Hard & Pale green & Yellow & Cream & Striped & White \\
\hline Nanhai 2 Aouri & CS & Matt & Spiny & Hard & Pale green & Yellow & Cream & Striped & White \\
\hline Nepal Local & CS & Glossy & Spiny & Intermediate & Brown & Absent & Absent & Striped & White \\
\hline Shantung Thorny & CS & Intermediate & Spiny & Hard & Yellow & Absent & Absent & Spotted & White \\
\hline AAUC-2 & CS & Matt & Spiny & Hard & Brown & Orange & Cream & Netted & White \\
\hline Perundurai & CS & Intermediate & Spiny & Hard & Pale green & Green & White & Netted & Cream \\
\hline IC-4079 & CS & Matt & Rough & Hard & Brown & Yellow & Others & Spotted & White \\
\hline N-78 & $\mathrm{CM}$ & Glossy & Smooth & Intermediate & Green & Yellow & Cream & Spotted & White \\
\hline Mysore & $\mathrm{CM}$ & Matt & Smooth & Intermediate & Yellow & Absent & Absent & Spotted & White \\
\hline CM-1 & $\mathrm{CM}$ & Glossy & Smooth & Hard & Dark green & Pale green & Cream & Spotted & White \\
\hline Olakkur & $\mathrm{CM}$ & Intermediate & Smooth & Soft & Pale green & Yellow & Cream & Spotted & Cream \\
\hline
\end{tabular}


TABle 5: Continued.

\begin{tabular}{|c|c|c|c|c|c|c|c|c|c|}
\hline Accession & Species & PL & SS & SC & SPD & SPT & LS & LM & $\mathrm{LC}$ \\
\hline Mayilam & $\mathrm{CM}$ & Intermediate & Smooth & Hard & Yellow & Dark green & White & Netted & Cream \\
\hline Muskmelon Orange & $\mathrm{CM}$ & Glossy & Others & Hard & Yellow & Dark green & Cream & Short streaked & White \\
\hline Pudukkottai & $\mathrm{CM}$ & Glossy & Smooth & Hard & Yellow & Pale green & Orange & Netted & White \\
\hline Theni & $\mathrm{CM}$ & Intermediate & Smooth & Soft & Yellow & Dark green & Cream & Short streaked & White \\
\hline Andaman & $\mathrm{CM}$ & Intermediate & Smooth & Soft & Yellow & Pale green & Orange & Spotted & White \\
\hline
\end{tabular}

Note. CS: C. sativus, CM: C. melo.

TABLE 6: Eight quantitative characters contribution to three principle components.

\begin{tabular}{lccc}
\hline Quantitative character & PC1 & PC2 & PC3 \\
\hline No. of primary branches & 0.041 & 0.027 & 0.457 \\
Internodal length & 0.086 & 0.046 & 0.422 \\
Leaf petiole length & -0.047 & -0.001 & 0.452 \\
Leaf length & 0.053 & 0.016 & 0.385 \\
Leaf width & 0.017 & -0.029 & 0.487 \\
Peduncle length & -0.008 & 0.068 & -0.135 \\
Fruit length & 0.935 & 0.329 & -0.065 \\
Fruit girth & -0.332 & 0.939 & 0.007 \\
\hline
\end{tabular}

greater than the other two. Group 3 contained the least number of accessions, that is, C. melo cultivars only. Group 1 was mainly constituted of $C$. sativus accessions, while Group 2 and Group 3 contained most of $C$. melo accessions. The dispersion among $C$. melo accessions was greater than that among $C$. sativus accessions.

Characteristics on twenty-three qualitative traits of eighteen accessions are shown in Table 5. Traits observed were varied from stem characters, leaf characters, fruit characters and seed characters. Same growth patterns were shown in all the plants observed and all of them were indeterminate. For stem characters, all of the accessions had angular stems with different degrees of green color. C. sativus "Long Green" was the only one with light green stem, which was lighter than the others. Besides, C. sativus "AAUC-2" displayed sparse stem pubescence and $C$. sativus "JL-3 Dhillon", $C$. sativus "Nepal Local", "Perundurai," and "IC-4079" showed dense stem pubescence. Other accessions were between them. For leaf characters, five types of leaf shape were recorded, namely, entire, cordate, triangular, reniform, and pentalobate. Among them, the entire shape was common, including ten accessions showing entire leaves with spiny margin. All accessions had green leaves with different density, and C. sativus "Perundurai" was the only one without leaf glossiness. Pubescence was also observed on leaves as on stems in all accessions, and the leaf pubescence was softer than those on stem. The pubescence trait is closely related to plant defense system. It is under investigation for map-based cloning by SSR markers. The biggest diversity appeared on the fruit-related characteristics, as shown with the results of quantitative characteristics. Except C. sativus "AAUC-2", the fruit shapes of all the $C$. sativus accessions were elongated. For C. melo accessions, fruit shapes of C. melo "Mayilam" and "CM-1" were pyriform. C. melo "Mysore" was only elliptical and C. melo "Muskmelon Orange" and "Theni" were globular. Fruit characters were further recorded on fruit skin luster, texture, and hardness, which are related to the appearance and taste. C. sativus "Nanhai 2 Aouri", "AAUC-2", "IC-4079", and C. melo "Mysore" did not have fruit skin luster. Fruit skin textures of all the $C$. melo accessions were smooth and those of $C$. sativus accessions were rough or spiny. Three C. melo accessions, "Olakkur", "Theni", and "Andaman," had soft fruit skins. C. sativus "Nepal local", C. melo "N-78", and "Mysore" had harder fruit skin than C. melo "Olakkur", "Theni", and "Andaman", but softer than the others. Besides, all of accessions had yellow flowers and white or cream seeds, expect that the seeds of "Long Green" were green.

3.2. Phylogenetic Analysis. The lengths of matK and $r b c L$ genes ranged from 750 to $1067 \mathrm{bp}$, sequences were submitted to DNA Database of Japan (DDBJ). The aligned data matrix combined with matK and $r b c L$ gene was $1,728 \mathrm{bp}$ long. Based on the aligned matrix, phylogenetic trees were made by Neighbor-joining and maximum likelihood method (Figures 4 and 5).

On the topology of C. sativus, "JL-3 Dhillon" showed divergence from other accessions. Fruit morphologies of "JL-3 Dhillon", the longest fruit length and yellow fruit skin, differed from other C. sativus (Tables 4 and 5). In a previous phylogenetic study of Cucumis, some special morphological traits were circumscribed within some certain clades [5]. Species of the Asian/Australian clade had more of less ellipsoid fruits that stay green or turn yellow-orange at maturity. C. ritchiei/C. maderaspatanus clade was characterized by smooth and round fruits that turn red at maturity [5]. Also here in the present study, this correlation between morphological traits and clade divergence at molecular level was shown in the case of "JL-3 Dhillon".

CGN23965 "I.C 4079" has the scientific name C. sativus group Gherkin, while CGN24494 "Nepal local" has the scientific name C. sativus var. sikkimensis (TANU and CGN). In the phylogenetic tree, "I.C 4079" and "Nepal local" did not show big divergence with other accessions, both of them were nested in the same clade. Two Chinese $C$. sativus accessions "Cus 125/71" and "Nanhai 2 Aouri" were nested in the same clade as well as the accessions from different areas, India and Nepal. One of reasons for narrow molecular divergence could be due to the accessions derived from narrow areas of India and Himalaya. 


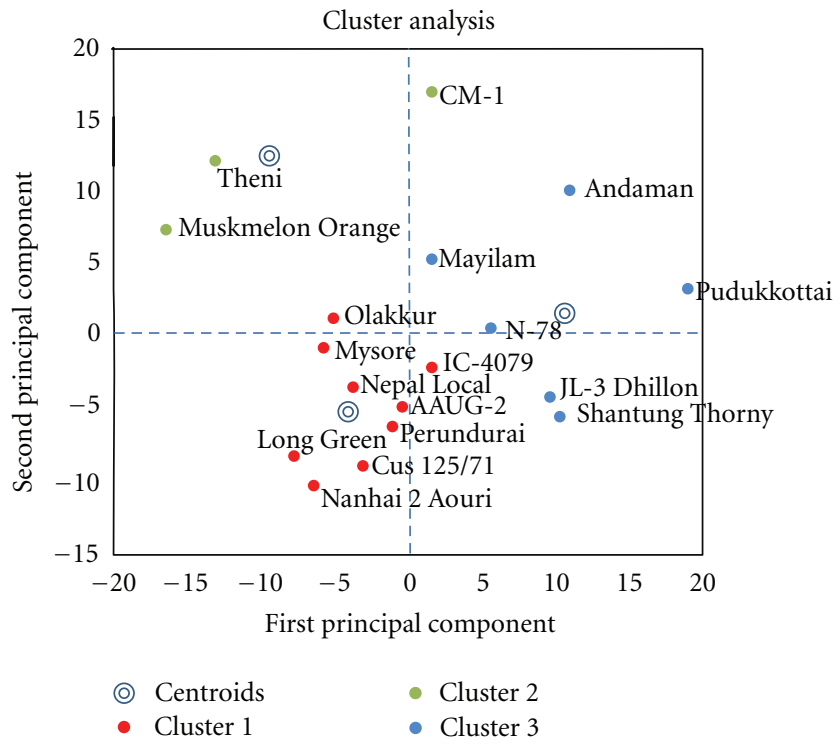

(a)

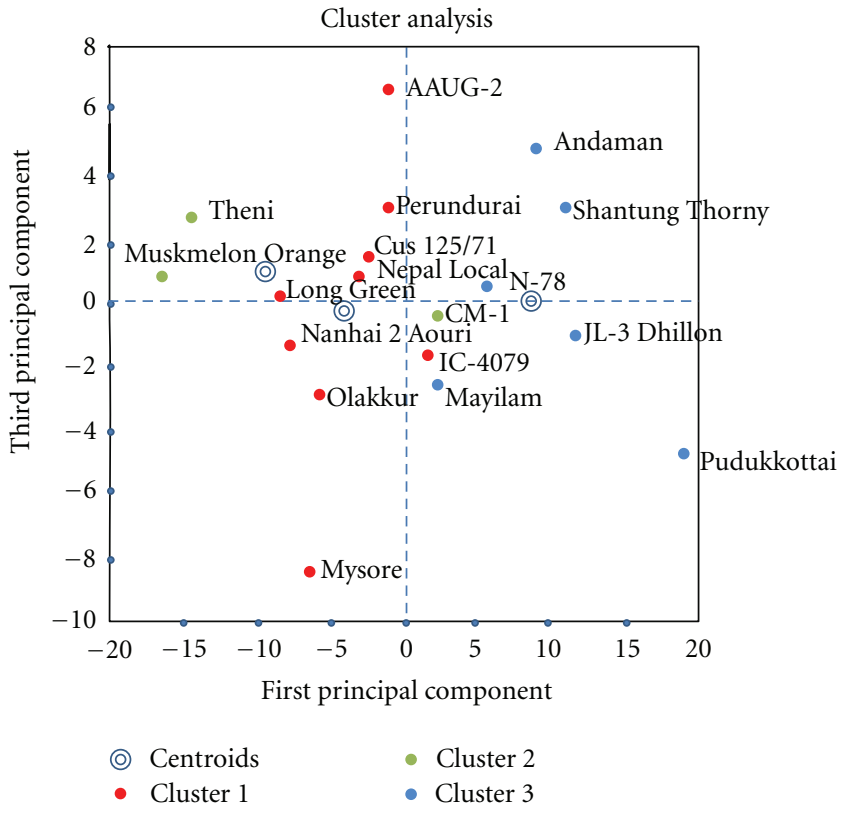

(b)

Figure 3: (a) Distribution of eighteen accessions on the first and second principle components; (b) distribution of eighteen accessions on the first and third principle components.

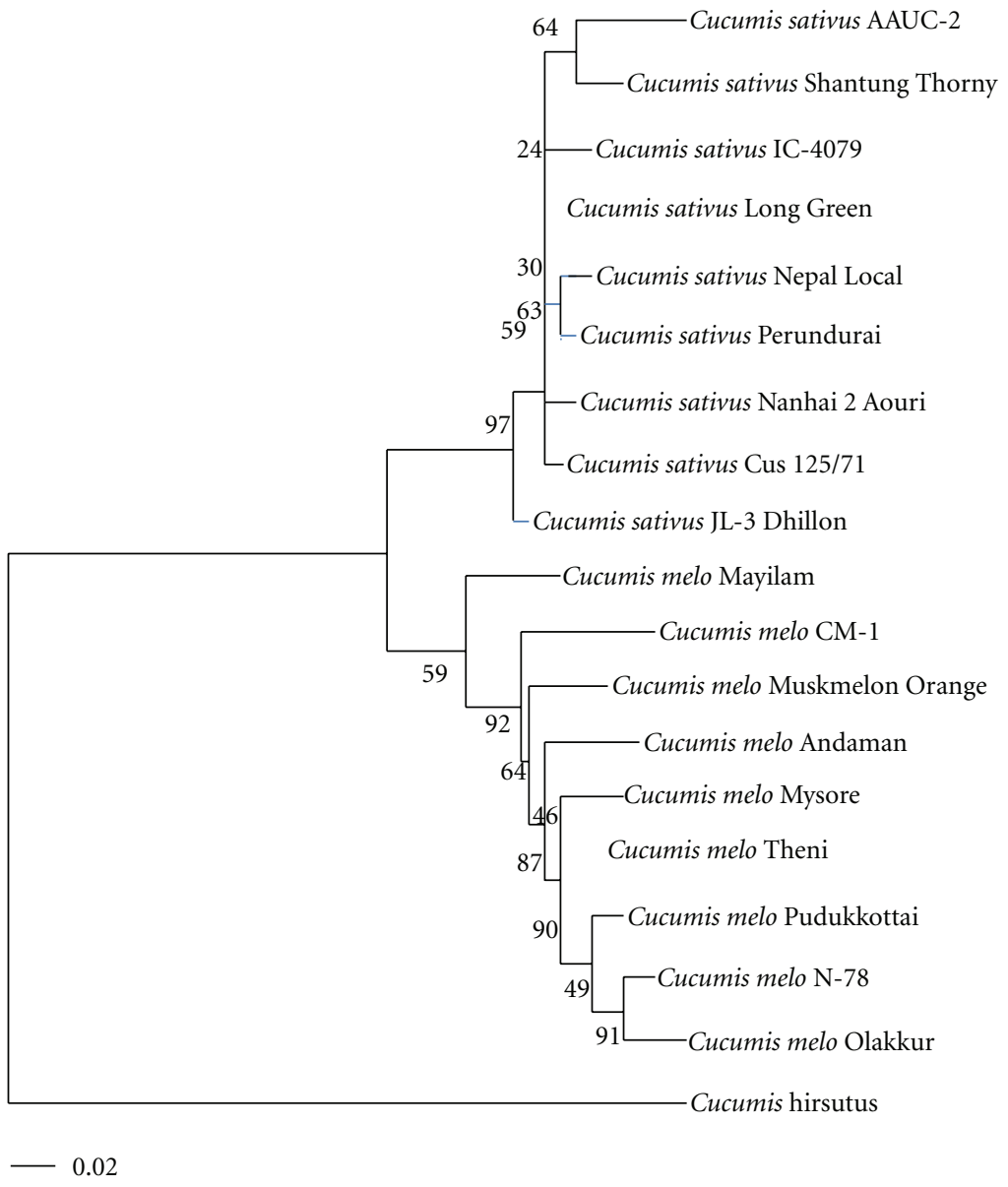

FIgURE 4: Neighbor-joining tree for 18 accessions in this study based on combined sequence of $r b c L$ and matK genes. The tree is rooted on Cucumis hirsutus. Bootstrap values based on 1000 replicates above branches. 


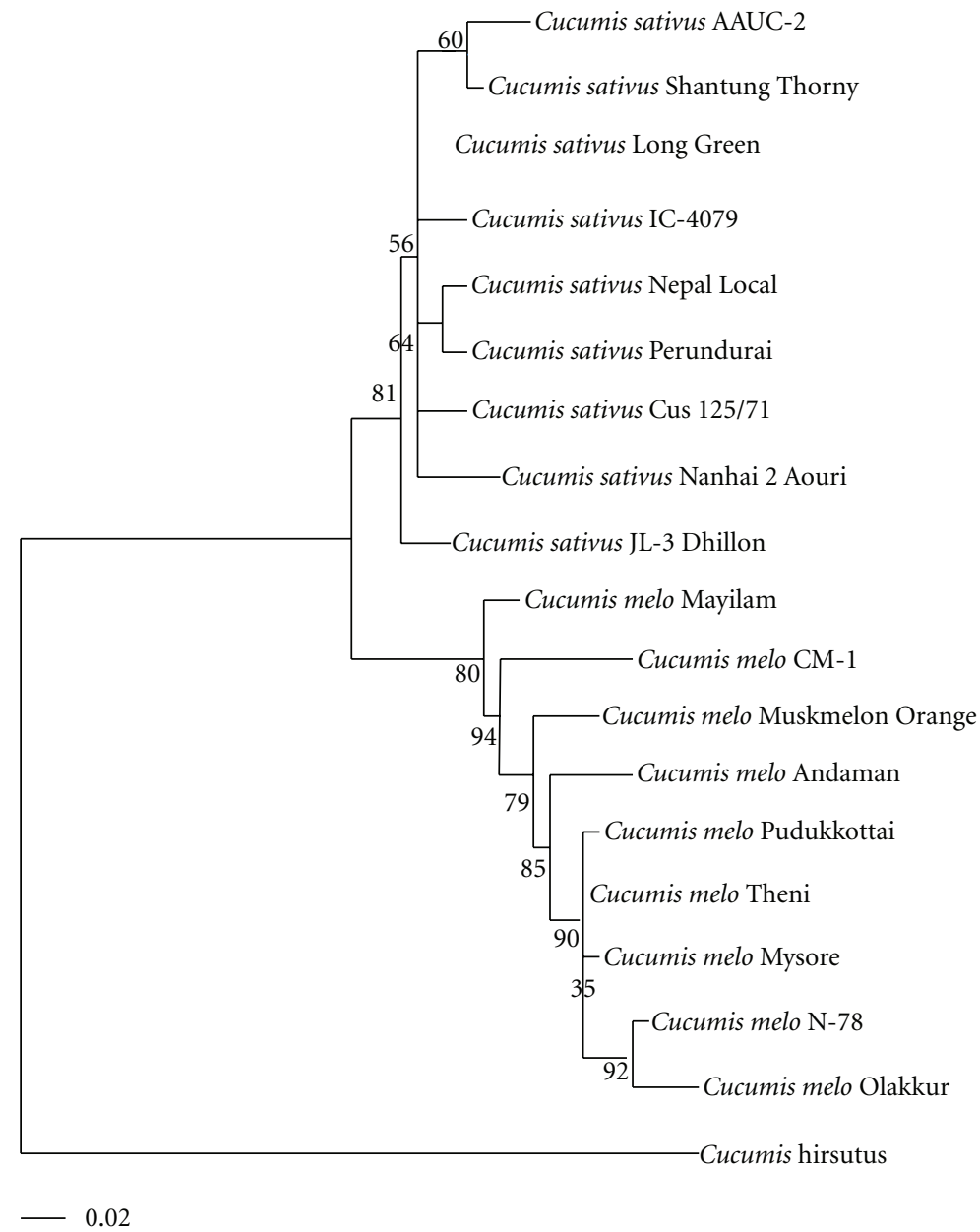

Figure 5: Maximum likelihood tree for 18 accessions in this study based on combined sequence of $r b c L$ and matK genes. The tree is rooted on Cucumis hirsutus. Bootstrap values based on 1000 replicates above branches.

According to the previous works and present study, comparing with $C$. sativus, genetic diversity in C. melo seems to be much bigger. African melon group has 30 species that is divided into six subgroups [2], and ancient melon varieties were distributed throughout South Asia, which could be the first genetic diversity center [7]. C. melo accessions studied in the present study were mainly introduced from three institutions, namely, India Institute of Vegetable Research (IIVR), Tamil Nadu Agricultural University (TNAU), and National Bureau of Plant Genetic Resources (NBPGR), USA. They distributed all around India, but in the phylogenetic tree, the accessions from different places nested in the same clade with each other. A big divergent node was found with C. melo "CM1", branching with the other accessions. Special morphological traits were also found in accession "CM1", such as the longest intermodal length and unique fruit color (Figure 2). "Muskmelon Orange" branch was close to "CM1", and they were grouped into Cluster 2 in the cluster analysis (Figure 3).

The fruit shapes of C. melo "Muskmelon Orange" and "Theni" were globular, being distinguished from the other
C. melo accessions. This discrepancy was not supported by the phylogenetic results. Besides, C. melo "Mayilam" branch was the biggest divergent node. It shared the same group with "N-78" in cluster analysis in spite of that they were far from each other in phylogenetic trees. So in C. melo, correlations between morphological traits and phylogenetic tree were not as supportive as those in Cucumis sativus. It could be concluded that $C$. melo holds bigger diversity in morphology than C. sativus, which has caused more complex factors for analyzing phylogenetic relationships.

\section{Conclusion}

Eighteen Cucumis accessions derived from south Asia, which represent the most diverse genetic resources, were evaluated morphologically and at the molecular level. It was shown that, although large morphological diversity was found among C. melo and C. sativus accessions, genetic diversity based on the molecular analysis showed larger diversity in C. melo than in C. sativus. Thus, it would be necessary to investigate phylogenetic relationships at the molecular 
level among Cucumis species using accessions collected more widely in Asia, Africa, and Australia continents. Also, the accessions studied here are new germplasms and could be alternative candidates for breeding programs in this area.

\section{Authors' Contribution}

C. Zhang and A. S. Pratap contributed equally to this work.

\section{Akcnowledgments}

A part of the present work was carried out at Chiba University while C. Zhang and A. S. Pratap were the recipients of the Japanese Government (Monbukagakusho) scholarship based on the Agreements between Chiba University and Shanghai Jiao Tong University and Tamil Nadu Agricultural University, respectively.

\section{References}

[1] FAOSTAT, "Statistical database (online) of Food and Agriculture Organization of the United Nations," http://faostat .fao.org/, 2008.

[2] J. H. Kirkbride Jr., Biosystematic Monograph of the Genus Cucumis (Cucurbitaceae), Parkway, Boone, NC, USA, 1993.

[3] C. Jeffrey, "A review of the Cucurbitaceae," Botanical Journal of the Linnean Society, vol. 81, pp. 233-247, 1980.

[4] T. W. Whitaker and G. N. Davism, Cucurbits: Botany, Cultivation, and Utilization, Interscience, New York, NY, USA, 1962.

[5] P. Sebastian, H. Schaefer, I. R. H. Telford, and S. S. Renner, "Cucumber (Cucumis sativus) and melon (C. melo) have numerous wild relatives in Asia and Australia, and the sister species of melon is from Australia," Proceedings of the National Academy of Sciences of the United States of America, vol. 107, no. 32, pp. 14269-14273, 2010.

[6] J. E. Staub, F. C. Serquen, and J. D. McCreight, "Genetic diversity in cucumber (Cucumis sativus L.): III. An evaluation of indian germplasm," Genetic Resources and Crop Evolution, vol. 44, no. 4, pp. 315-326, 1997.

[7] R. W. Robinson and D. S. Decker-Walters, Cucurbits, CAB International, New York, NY, USA, 1997.

[8] E. Nakata, J. E. Staub, A. I. López-Sesé, and N. Katzir, "Genetic diversity of Japanese melon cultivars (Cucumis melo L.) as assessed by random amplified polymorphic DNA and simple sequence repeat markers," Genetic Resources and Crop Evolution, vol. 52, no. 4, pp. 405-419, 2005.

[9] F. S. Luan, I. Delannay, and J. E. Staub, "Chinese melon (Cucumis melo L.) diversity analyses provide strategies for germplasm curation, genetic improvement, and evidentiary support of domestication patterns," Euphytica, vol. 164, no. 2, pp. 445-461, 2008.

[10] Y. Aierken, Y. Akashi, P. T. P. Nhi et al., "Molecular analysis of the genetic diversity of Chinese Hami melon and Its Relationship to the melon germplasm from Central and South Asia," Journal of the Japanese Society for Horticultural Science, vol. 80, no. 1, pp. 52-65, 2011.

[11] T. K. Behera, A. K. Singh, and J. E. Staub, "Comparative analysis of genetic diversity in Indian bitter gourd (Momordica charantia L.) using RAPD and ISSR markers for developing crop improvement strategies," Scientia Horticulturae, vol. 115, no. 3, pp. 209-217, 2008.
[12] W. W. Zhang, H. L. He, Y. Guan et al., "Identification and mapping of molecular markers linked to the tuberculate fruit gene in the cucumber (Cucumis sativus L.)," Theoretical and Applied Genetics, vol. 120, no. 3, pp. 645-654, 2010.

[13] Z. Fan, M. D. Robbins, and J. E. Staub, "Population development by phenotypic selection with subsequent markerassisted selection for line extraction in cucumber (Cucumis sativus L.)," Theoretical and Applied Genetics, vol. 112, no. 5, pp. 843-855, 2006.

[14] S. M. Chung, J. E. Staub, and J. F. Chen, "Molecular phylogeny of Cucumis species as revealed by consensus chloroplast SSR marker length and sequence variation," Genome, vol. 49, no. 3 , pp. 219-229, 2006.

[15] S. S. Renner, H. Schaefer, and A. Kocyan, "Phylogenetics of Cucumis (Cucurbitaceae): Cucumber (C. sativus) belongs in an Asian/Australian clade far from melon (C. melo)," BMC Evolutionary Biology, vol. 7, p. 58, 2007.

[16] J. J. Doyle and J. L. Doyle, "A rapid DNA isolation procedure for small quantities of fresh leaf tissue," Phytochemical Bulletin, vol. 19, pp. 11-15, 1987.

[17] A. I. López-Sesé, J. E. Staub, and M. L. Gomez-Guillamon, "Genetic analysis of Spanish melon (Cucumis melo L.) germplasm using a standardized molecular-marker array and geographically diverse reference accessions," Theoretical and Applied Genetics, vol. 108, no. 1, pp. 41-52, 2003.

[18] S. Escribano and A. Lázaro, "Agro-morphological diversity of Spanish traditional melons (Cucumis melo L.) of the Madrid provenance," Genetic Resources and Crop Evolution, vol. 56, no. 4, pp. 481-497, 2009. 


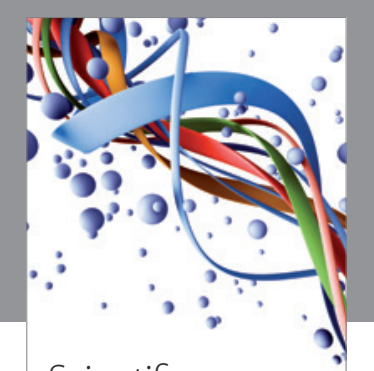

Scientifica
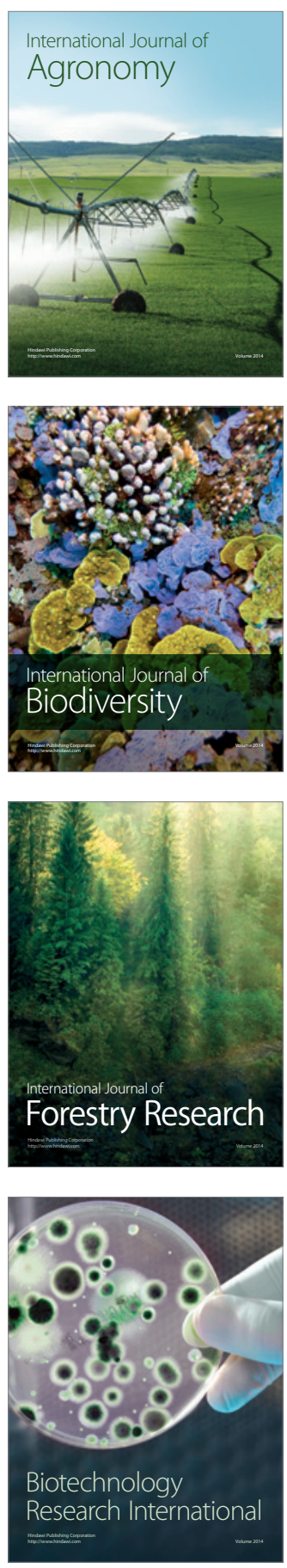
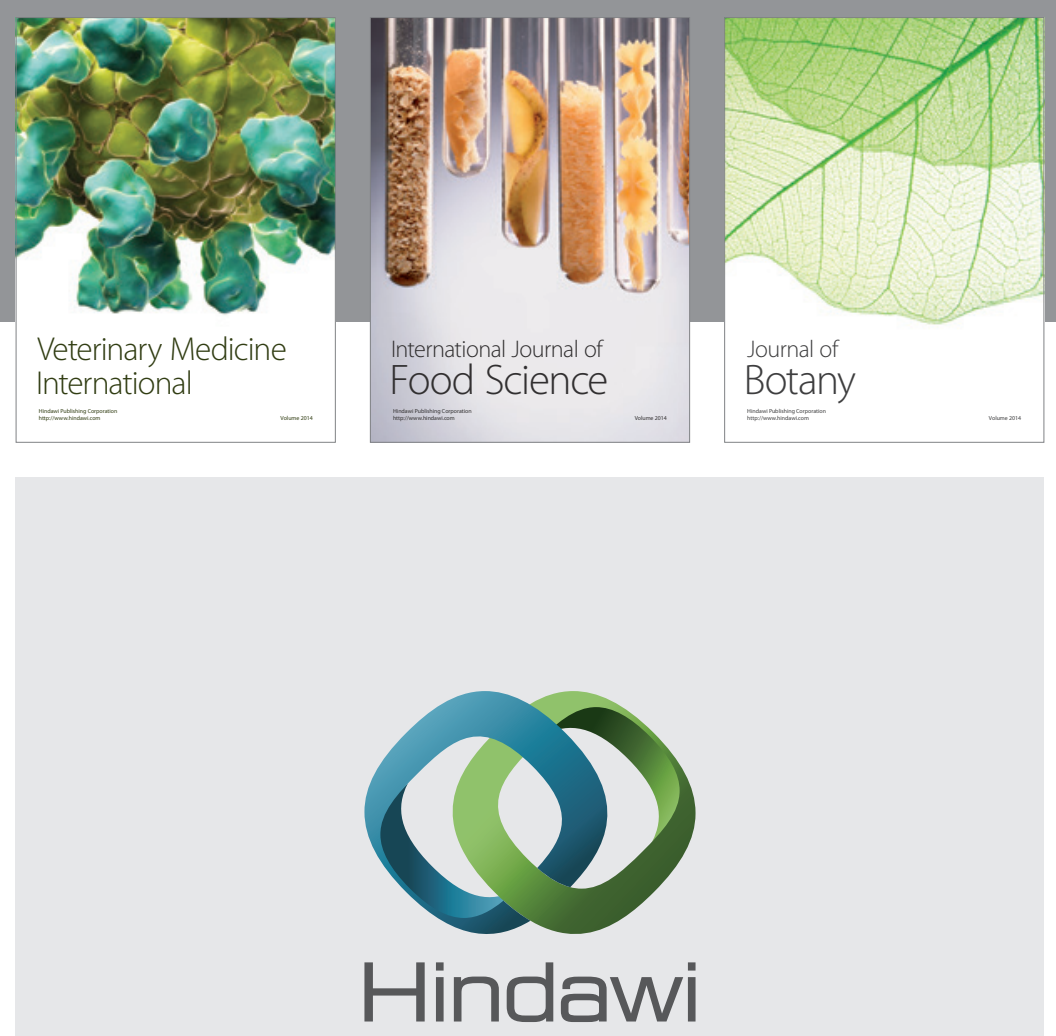

Submit your manuscripts at

http://www.hindawi.com
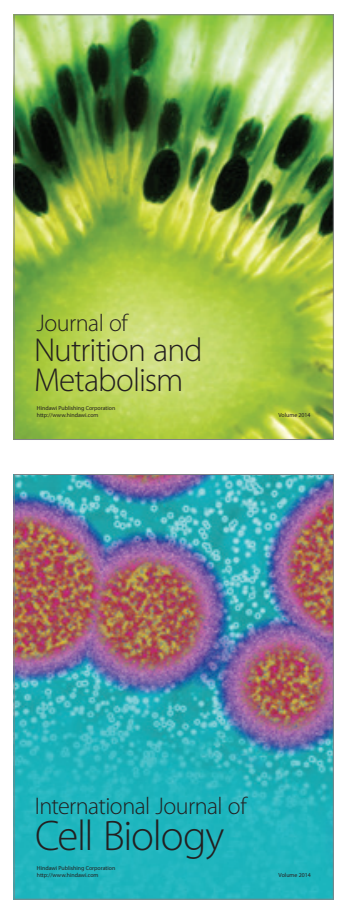
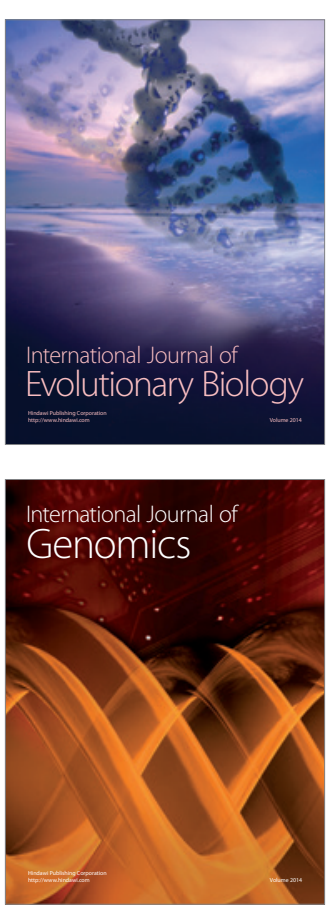
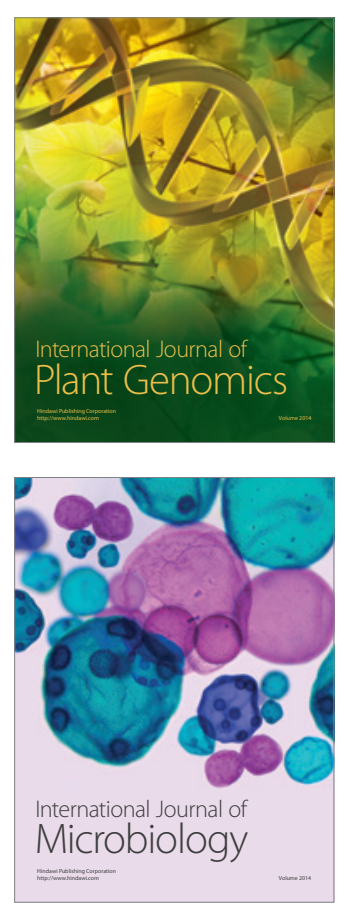

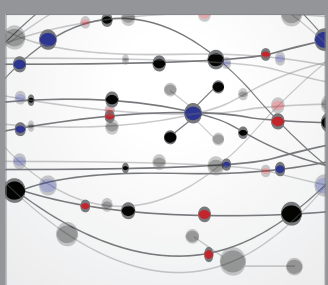

The Scientific World Journal
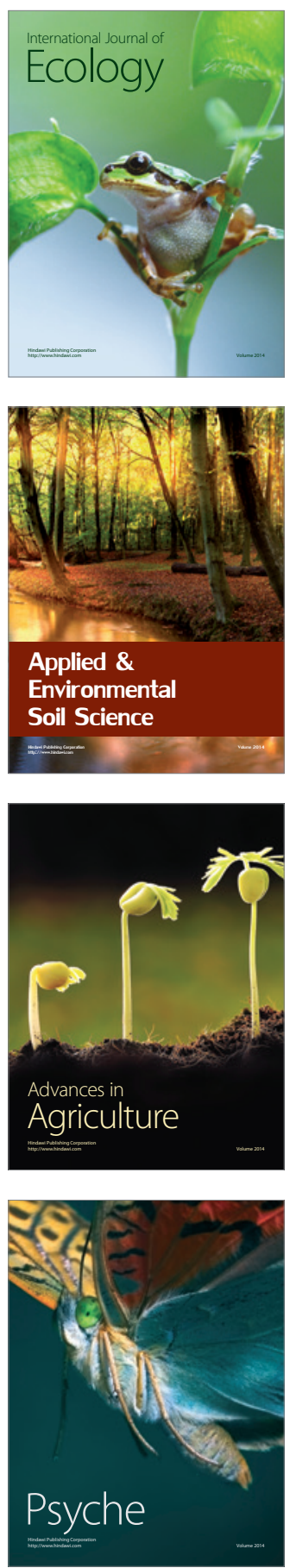